\title{
Políticas educacionais: implementação ou atuação?
}

\author{
Patrícia de Faria Ferreira' \\ Rede Estadual de Ensino do Rio Grande do Sul, Professora
}

\begin{abstract}
BALL, S. J.; MAGUIRE, M.; BRAUN, A. Como as escolas fazem as políticas: atuação em escolas secundárias. Tradução Janete Bridon. Ponta Grossa: Ed. UEPG, 2016. 220 p.
\end{abstract}

Este texto traz como temática principal a implementação de políticas educacionais e discute o que dentro desse campo tem se constituído como um paradigma. Segundo alguns estudiosos, o termo implementação não é capaz de "alcançar" o que de fato acontece com as políticas em ação, por isso a proposta para pesquisadores é compreender a atuação das políticas. Para entender melhor como essa mudança de perspectiva na análise de pesquisas educacionais está se constituindo, recorro a um estudo realizado por Stephen Ball, Meg Maguire e Annette Braun.

○ livro apresenta uma pesquisa realizada em quatro escolas secundárias da Inglaterra. É a partir daí que os autores retomam o que Ball já argumentava em relação à implementação das políticas. Para ele esse termo não é capaz de descrever ou representar a complexidade do processo de pensar e saber como são feitas as políticas. Na apresentação à edição brasileira, é defendida a ideia de atuação das políticas e não de implementação de políticas, introduzindo e ampliando a teoria policy enactment, base teórica que fundamenta o processo empírico e de análise da pesquisa. A tradução da palavra enactment não é fácil. Assim, para compreender esse conceito, é preciso contextualizá-lo no sentido teatral, como formas de interpretação e atuação dos envolvidos no processo das políticas.

A premissa do livro é pensar a prática e a política (policy) de uma forma diferente, buscando a erradicação do que os autores chamam de "binário enganoso". Para tanto, propõem um diálogo com os formuladores de políticas, os que trabalham nas escolas e os pesquisadores da área de análise de políticas. Para os primeiros, gostariam de argumentar que as políticas não

\footnotetext{
Mestre em Ensino de Ciências e Matemática; Doutoranda em Educação pela Universidade Federal de Pelotas.
} 
podem ser pensadas a partir do que imaginam ser a escola ideal e em relação às diferenças entre as escolas: cada uma é única e, portanto, um lugar único de atuação. Quanto aos que trabalham nas escolas, o objetivo foi entender a tradução da política na prática, reconhecendo-os como atuantes, sujeitos da política e dos discursos que a constituem. Aos pesquisadores desse campo, o desafio foi problematizar o estudo das políticas nos contextos educacionais.

○apítulo 1, Fazendo pesquisa sobre atuação das políticas, propõe uma concepção para além da implementação, que auxilie os estudos sobre políticas educacionais a superar a visão superficial de política como texto legislativo e normativo, de cima para baixo e/ou vice-versa, objetivando a resolução de um determinado problema. Essa superação implica entender a política como um processo de diversos momentos, diferentes interpretações e atuações.

Os autores destacam a complexidade do processo de atuação das políticas, seu aspecto dinâmico e as diferentes trajetórias vivenciadas por diferentes atores em diversos locais. A política faz e é feita em espaços de disputas e acordos em relação às demais políticas vigentes, por meio de processos discursivos que permitem maior ou menor limitação de criatividade e de regimes de verdade, com sujeitos históricos interagindo em relações de poder.

É também no capítulo l que Ball, Maguire e Braun apresentam a estrutura da pesquisa, realizada entre os anos 2008 e 201 l, com dois objetivos principais, um relacionado ao desenvolvimento da teoria de atuação de políticas e outro voltado à questão empírica da atuação das políticas em contextos "semelhantes, mas diferentes". As questões centrais da pesquisa foram as seguintes: como indivíduos e grupos de atores diferentes interpretam e atuam a política em contextos específicos de múltiplas demandas de políticas, dados os recursos disponíveis para eles? Como e de que maneira fatores socioculturais, históricos e contextuais afetam as maneiras pelas quais as escolas atuam as políticas? Como diferenças entre escolas podem ser explicadas na atuação das políticas? 
Foi coletada uma variedade de dados, de documentação específica de cada escola a entrevistas semiestruturadas com as equipes gestoras, professores, funcionários, sindicatos e pessoal de apoio, analisados e interpretados em três facetas: o material, o interpretativo e o discursivo. A base da análise e interpretação é uma série de recursos teóricos, com influência do trabalho de Foucault sobre discurso e governamentalidade.

No capítulo 2, Levando o contexto a sério, os autores direcionam - olhar para aspectos específicos de cada escola, pois, para eles, muitos fatores que tencionam a ação da política são peculiares a cada instituição e devem ser considerados pelos pesquisadores. São muitas as variáveis locais, história, localização, prédio, condições materiais e tecnológicas, qualificação dos docentes e questões socioeconômicas, entre outras que "recebem" e dão forma às atuações da política. Segundo os autores, para a compreensão dessa atuação é preciso incorporar na análise a complexidade e a especificidade dos contextos.

No capítulo 3, Fazendo atuação: pessoas, significados e trabalho com as políticas, a ênfase está na hermenêutica da política, nas peças-chave da política, a tradução e a interpretação. Para distingui-las os autores caracterizam tradução como uma leitura inicial, uma decodificação da política em relação aos aspectos sociais, culturais e históricos da instituição como também das pessoas que nela trabalham. É dentro do processo de interpretação que surgem os questionamentos em torno da efetivação da política e também as estratégias de ação. Por vezes, tradução e interpretação andam juntas, sobrepostas em diferentes arenas, mas ambas atuam para inscrever o discurso nas práticas. Ainda nesse capítulo é apresentada a categorização dos atores da política e o trabalho com a política, ou seja, as diferentes posições assumidas pelos diferentes sujeitos em relação à interpretação e tradução da política: narradores, empreendedores, pessoas externas, negociantes, entusiastas, tradutores, críticos e receptores. Essas categorias não são fixas, e há mobilidade entre elas; algumas pessoas encontram-se em mais de uma posição. Mais uma vez são apontadas as diferentes formas de atuação das políticas nas mais diversas variáveis, não sendo possível compreendê-las apenas como implementação. 
Política de padrões é o foco do capítulo 4, Sujeitos da política: criatividade restrita e tecnologias de avaliação nas escolas, que trata também das orientações para o desenvolvimento da produtividade e dos mecanismos tecnológicos que dão visibilidade ao desempenho e à vida escolar de alunos e professores, no intuito de que ambos se mantenham ou se aproximem dos padrões e metas estabelecidas. A partir da obra de Foucault, os autores exploram como funcionam os discursos de padrões, as maneiras que as políticas são transformadas em prática por meio de um complexo de técnicas, de procedimentos e de artefatos, resistências e acomodações a esse discurso. É nesse capítulo que os autores apresentam um esquema que denominam cadeia de entrega, um método de reforma do setor público aplicado a diversas áreas. Deliverology é o processo sistemático de estimular o progresso e produzir resultados no governo e no setor público. Nas escolas envolvidas na pesquisa, a busca por resultados nas disciplinas, especialmente de inglês e matemática, gerou entre os professores conflitos e aumento de demanda. Ao longo do capítulo, os autores indicam as formas pelas quais a lógica do desempenho entra e envolve políticas institucionais e prioridades, prolifera as interações mais imediatas entre professores e seus alunos e afeta o modo pelo qual os professores pensam sobre si mesmo e seu trabalho.

O capítulo 5, Sujeitos da política: fazendo política de comportamento nas escolas, é sobre a predominância da política de comportamento nas escolas e sua constituição dentro e fora dos espaços escolares. Como dito no capítulo 4 , a política de padrões afeta o trabalho dos professores e a organização escolar como um todo, mas segundo os autores, a política de comportamento é ainda mais central nesses aspectos. Os governos mostram uma preocupação com a gestão do comportamento dos alunos, dos professores e da gestão; distintas políticas são formuladas para tratar comportamento e disciplina, e para colocálas em prática entram em cena assistentes de ensino e apoio à aprendizagem, psicólogos, mentores de aprendizado e afins. É nesse campo que estão abertas as possibilidades de negócios e "consumo de soluções". Com isso, disputam nessa arena de política de comportamento diversas práticas e perspectivas de formação profissional, além das variáveis apresentadas em cada contexto como tempo, local e questões histórico-sociais do conjunto de alunos a que se 
destinam as ações da política. A centralidade da política de comportamento é parte da preocupação com resultados de aprendizagem, visto que problemas de disciplina afetam diretamente o desempenho dos estudantes e a imagem da escola na comunidade. As instituições preocupam-se em demonstrar que sabem gerir os problemas comportamentais de seus alunos e que, para tanto, possuem um conjunto estratégico de profissionais, tecnologias e táticas. Convém lembrar que as quatro escolas dessa pesquisa estão imersas em políticas de resultados que disputam a escolha dos pais e, portanto, como apresentam os autores ao longo do capítulo, estão inundadas de políticas relacionadas ao "bom" comportamento.

É no capítulo 6, Artefatos da política: discursos, representações e traduções, que os autores, em uma perspectiva foucaultiana, direcionam a reflexão para o poder constitutivo de artefatos e discursos de governamentalidade produzidos pelas facetas das políticas. Os autores coletaram uma diversidade de dados visuais a partir dos quais procuram mostrar como esses artefatos transportam os discursos e fazem circular as políticas nas escolas, apresentando as produções discursivas e normativas em relação ao "bom aluno", à "boa escola" e ao "bom professor". Um "bom aluno", segundo o discurso dominante, é aquele que se comporta adequadamente, possui altas expectativas acadêmicas e acredita muito em si mesmo e no seu sucesso, a "boa escola" é produzida pelos níveis elevados de conquistas e dentro dessa lógica está o "bom professor". Ao longo do capítulo os autores colocam a complexidade dos discursos de política, artefatos e materiais que produzem efeitos nos processos de atuação das políticas.

O sétimo e último capítulo, Em direção a uma teoria de atuação, busca responder à questão central da pesquisa - como as escolas fazem as políticas - e elaborar uma teorização de atuação das políticas. Os autores retomam e reiteram a interação entre os dados e a teoria e elencam algumas considerações nesse sentido: a importância de práticas rotineiras e banais para que as políticas sejam colocadas em ação; a importância de artefatos para realização e representação da política na prática e os professores como "elaboradores de sentido" no fazer a política. As várias formas dos discursos que compõem as políticas e produzem sentidos e sujeitos também constituem 
a parte final do livro. Em síntese, os autores argumentam que muita atenção tem sido dada à avaliação de como as políticas se efetivam na prática, ou seja, o processo de implementação e a pouca atenção para as ações mais significativas em torno da política, que é a compreensão e documentação dos processos pelos quais as escolas lidam com as demandas das políticas.

Enfim, ao fazer a resenha de um livro, corre-se o risco quase inevitável de destacar alguns aspectos mais que outros ou, até mesmo, ocultar informações relevantes ao entendimento da obra. Como as políticas, trata-se de uma interpretação e tradução subjetivada a cada leitor, passível de tantas outras interpretações e traduções possíveis. Como as escolas fazem as políticas é leitura indispensável a pesquisadores de políticas educacionais, alunos e professores universitários da área da educação, estudiosos desse terreno na educação básica, governantes e formuladores de políticas, entre outros que se aventuram nesse campo. $\bigcirc$ trabalho dos autores proporciona um aprendizado de questões teóricas e empíricas em pesquisas de políticas educacionais. A leitura constitui um esfacelamento da ingenuidade em que é usada a expressão implementação. Assim, a partir desse estudo é possível compreender como os diferentes sujeitos em diferentes contextos colocam em ação a complexa teia de políticas e os seus impactos em cada um desses sujeitos e em suas instituições. A importância do livro reside também no fato de poder fundamentar e orientar, não como receita e sim como diretriz, qualquer trabalho no campo das políticas educacionais que vise a compreender como se fazem as políticas.

Recebida em 16 de fevereiro de 2018 Aceita em 10 de abril de 2018

Endereços para correspondência: Rua XV de Novembro, 286, Centro, 96310 000, Herval, Rio Grande do Sul, Brasil; patriciafariaf@hotmail.com 